\title{
Solubility of Anthracene in Binary Alkane + 2-Butanol Solvent Mixtures
}

\author{
Anita I. Zvaigzne and William E. Acree, Jr.* \\ Department of Chemistry, University of North Texas, Denton, Texas 76203-5068
}

\begin{abstract}
Experimental solubilities are reported for anthracene dissolved in six binary mixtures containing 2-butanol with $n$-hexane, $n$-heptane, $n$-octane, cyclohexane, methylcyclohexane, and $2,2,4$-trimethylpentane at $25^{\circ} \mathrm{C}$. Results of these measurements are used to test two mathematical representations based upon the combined nearly ideal binary solvent (NIBS)/Redlich-Kister equation and modified Wilson model. For the systems studied, the combined NIBS/Redlich-Kister and modified Wilson equations were found to provide very reasonable mathematical representations, with deviations between experimental and back-calculated values on the order of $\pm 1.5 \%$ or less.
\end{abstract}

\section{Introduction}

Solid-liquid equilibrium data of organic nonelectrolyte systems are becoming increasingly important in the petroleum industry, particularly in light of present trends toward heavier feedstocks and known carcinogenicity/mutagenicity of many of the larger polycyclic aromatic compounds. Solubility data for a number of polycyclic aromatic hydrocarbons (1-5) (i.e., anthracene and pyrene) and heteroatom polynuclear aromatics (6-9) (i.e., carbazole, dibenzothiophene, and xanthene) have been published in the recent chemical literature. Despite efforts by experimentalists and scientific organizations, both in terms of new experimental measurements and criticallyevaluated data compilations, there still exist numerous systems for which actual solubility data are not reasily available.

To address this problem, researchers have turned to group contribution methods and semiempirical expressions to predict desired quantities. Group contribution methods have proved fairly successful in estimating solid solubility in pure and binary solvent mixtures from structural information. Practical application though is limited to systems for which all group interaction parameters are known. Generally, interaction parameters are evaluated from solid-liquid and liquid-vapor equilibrium data. It is important that the data base contain as many different functional groups as possible, preferably with adequate representation from both monoand multifunctional solute/solvent molecules to permit evaluation of potential synergistic effects. The data base should contain sufficient experimental values near infinite dilution in the event that one wishes to determine separate interaction parameters for finite concentration and infinite dilution activity coefficient predictions. The UNIFAC model (10) now has two sets of group interaction parameters, with the publication of the infinite dilution values by Bastos et al. (11).

Predictive expressions for solid-liquid equilibria have also been derived from simple thermodynamic mixing models. The nearly ideal binary solvent (NIBS) model (12-14) developed previously provides a relatively simple method for estimating the excess partial molar properties of a solid, $Z_{\mathrm{A}}^{\mathrm{E}}$, at infinite dilution in a binary solvent (components $\mathrm{B}$ and C)

* To whom correspondence should be addressed.

$$
\begin{gathered}
Z_{\mathrm{A}}^{\mathrm{E}}=f_{\mathrm{B}}^{\circ}\left(Z_{\mathrm{A}}^{\mathrm{E}}\right)_{\mathrm{B}}+f_{\mathrm{C}}{ }^{\circ}\left(Z_{\mathrm{A}}^{\mathrm{E}}\right)_{\mathrm{C}}-\Gamma_{\mathrm{A}}\left(x_{\mathrm{B}}{ }^{\circ} \Gamma_{\mathrm{B}}+x_{\mathrm{C}}{ }^{\circ} \Gamma_{\mathrm{C}}\right)^{-1} Z_{\mathrm{BC}}^{\mathrm{E}} \\
f_{\mathrm{B}}^{\circ}=1-f_{\mathrm{C}}^{\circ}=x_{\mathrm{B}}{ }^{\circ} \Gamma_{\mathrm{B}} /\left(x_{\mathrm{B}}{ }^{\circ} \Gamma_{\mathrm{B}}+x_{\mathrm{C}}{ }^{\circ} \Gamma_{\mathrm{C}}\right)
\end{gathered}
$$

in terms of a weighted mole fraction average of solute properties in the two pure solvents, $\left(Z_{\mathrm{A}}^{\mathrm{E}}\right)_{\mathrm{B}}$ and $\left(Z_{\mathrm{A}}^{\mathrm{E}}\right)_{\mathrm{C}}$, and a contribution due to the unmixing of the solvent pair by the presence of the solute. Equation 1 with $Z^{E}=G^{E}$ gives accurate predictions for naphthalene, iodine, $p$-dibromobenzene, benzil, $p$-benzoquinone, biphenyl, tolylacetic acid, thianthrene, carbazole, benzoic acid, and phenylacetic acid solubilities in systems of nonspecific physical interactions when molar volumes are used as weighting factors $\left(\Gamma_{i}=V_{i}\right)(9,14-18)$. Approximation of weighting factors with molecular surface areas enables eq 1 to provide accurate predictions for anthracene (1) and pyrene (3) solubilities in binary solvent mixtures containing benzene.

Continued development of solution models for describing the thermodynamic properties of a solute in binary solvent systems requires that a large data base be available for assessing the applications and limitations of derived expressions. Currently, only a limited data base exists for crystalline nonelectrolyte solubility in binary solvent mixtures. For this reason, anthracene solubilities were determined in six alkane +2 -butanol mixtures. Results of these measurements are used to further test the descriptive abilities of several previously derived expressions.

\section{Experimental Methods}

Anthracene (Aldrich, 99.9+\%) was used as received. Cyclohexane (Aldrich, HPLC), $n$-hexane (Aldrich, 99\%), $n$-heptane (Aldrich, HPLC), $n$-octane (Aldrich, $99+\%$, anhydrous), methylcyclohexane (Aldrich, $99+\%$, anhydrous), and 2,2,4-trimethylpentane (Aldrich, HPLC) were stored over molecular sieves to remove trace water shortly before use. 2-Butanol (Aldrich, $99+\%$, anhydrous) was stored over both anhydrous sodium sulfate and molecular sieves before being fractionally distilled. Gas chromatographic analysis showed solvent purities to be $99.7 \mathrm{~mol} \%$ or better. Karl-Fisher titration gave water contents (mass $/$ mass \%) of $<0.01 \%$ for 2-butanol. Binary solvent mixtures were prepared by mass so that compositions could be calculated to 0.0001 mole fraction.

Excess solute and solvent were placed in amber glass bottles and allowed to equilibrate in a constant-temperature water bath at $25.0 \pm 0.1{ }^{\circ} \mathrm{C}$ for several days. Attainment of 
Table 1. Experimental Mole Fraction Solubilities of Anthracene (A) in Binary Alkane + 2-Butanol Solvent Mixtures at $25.0^{\circ} \mathrm{C}$

\begin{tabular}{|c|c|c|c|c|c|}
\hline$x_{c}{ }^{0}$ & $x_{A^{\text {at }}}$ & $x_{c}^{0}$ & $x_{A}^{\text {nat }}$ & $x_{c}{ }^{0}$ & $x_{A}^{\text {ant }}$ \\
\hline \multicolumn{6}{|c|}{ n-Hexane (B) + 2-Butanol (C) } \\
\hline $\begin{array}{l}0.0000 \\
0.1432\end{array}$ & $\begin{array}{l}0.001274 \\
0.001311 \\
0.001282\end{array}$ & $\begin{array}{l}0.4851 \\
0.5863 \\
0.6820\end{array}$ & $\begin{array}{l}0.001169 \\
0.001070 \\
0.000969\end{array}$ & $\begin{array}{l}0.8497 \\
0.9249 \\
1.0000\end{array}$ & \\
\hline & $\begin{array}{cc} & n-\mathrm{H} \\
0.001571 \\
0.001541 \\
0.001476\end{array}$ & ptane (B & $\begin{array}{c}+ \text { 2-Butano } \\
0.001280 \\
0.001163 \\
0.001041\end{array}$ & $\begin{array}{l}(\mathrm{C}) \\
0.8693 \\
0.9328 \\
1.0000\end{array}$ & \\
\hline $\begin{array}{l}0.0000 \\
0.1724 \\
0.3201\end{array}$ & $\begin{array}{l}n-C \\
388 \\
83\end{array}$ & ctane (B) & $\begin{array}{c}+2 \text {-Butanol } \\
0.001412 \\
0.001263 \\
0.001111\end{array}$ & $\begin{array}{l}0.8791 \\
0.9353 \\
1.0000\end{array}$ & \\
\hline $\begin{array}{l}0.0000 \\
0.1266 \\
0.2285\end{array}$ & $\begin{array}{l}\text { Cycl } \\
353 \\
18\end{array}$ & hexane ( & $\begin{array}{c}+2 \text {-Butan } \\
0.001370 \\
0.001247 \\
0.001088\end{array}$ & $\begin{array}{l}1(\mathrm{C}) \\
0.8210 \\
0.9089 \\
1.0000\end{array}$ & \\
\hline $\begin{array}{l}0.0000 \\
0.1460 \\
0.2585\end{array}$ & $\begin{array}{l}\text { lethylc } \\
1649 \\
1725 \\
1647\end{array}$ & $\begin{array}{c}\text { clohexan } \\
0.4740 \\
0.5832 \\
0.6743\end{array}$ & $\begin{array}{l}\text { (B) }+2-\mathrm{Bu} \\
0.001413 \\
0.001262 \\
0.001117\end{array}$ & $\begin{array}{c}\text { anol (C) } \\
0.8541 \\
0.9234 \\
1.0000\end{array}$ & \\
\hline $\begin{array}{l}0.0000 \\
0.1574 \\
0.3118\end{array}$ & $\begin{array}{l}2,2,4-T r i m \\
0.001074 \\
0.001116 \\
0.001091\end{array}$ & $\begin{array}{c}\text { thylpent } \\
0.5396 \\
0.6365 \\
0.7292\end{array}$ & $\begin{array}{c}\text { ne (B) + 2-E } \\
0.001000 \\
0.000935 \\
0.000863\end{array}$ & $\begin{array}{c}\text { utanol (C } \\
0.8766 \\
0.9475 \\
1.0000\end{array}$ & $\begin{array}{l}0.000720 \\
0.000646 \\
0.000585\end{array}$ \\
\hline
\end{tabular}

equilibrium was verified by repetitive measurements after several additional days and by approaching equilibrium from supersaturation by preequilibrating the solutions at a higher temperature. Aliquots of saturated anthracene solutions were transferred through a coarse filter into a tarred volumetric flask to determine the amount of sample and diluted quantitatively with methanol. Concentrations were determined spectrophotometrically at $356 \mathrm{~nm}$ on a Bausch and Lomb Spectronic 2000. Experimental anthracene solubilities in the six binary alkane +2 -butanol mixtures studied are listed in Table 1. Numerical values represent the average of between four and eight independent determinations, with the measured values being reproducible to within $\pm 1 \%$. Experimental anthracene solubilities in the pure alkane solvents are in excellent agreement with published values in the chemical literature (1).

\section{Results and Discussion}

Expressions for predicting the thermodynamic properties of ternary nonelectrolyte systems have served as the point of departure for mathematical representation of experimental excess molar Gibbs energy, excess molar heat capacity, excess molar enthalpy, and excess molar volume data. Differences between predicted and observed values are expressed as

$$
\left(Z_{\mathrm{ABC}}^{\mathrm{E}}\right)^{\text {exp }}-\left(Z_{\mathrm{ABC}}^{\mathrm{E}}\right)^{\text {calc }}=x_{\mathrm{A}} x_{\mathrm{B}} x_{\mathrm{C}} Q_{\mathrm{ABC}}
$$

with $Q$ functions of varying complexity. For most systems encountered, the experimental data can be adequately represented by a power series expansion

$$
\begin{aligned}
Q_{\mathrm{ABC}}=A_{\mathrm{ABC}}+ & \sum_{i=1}^{r} B_{\mathrm{AB}}^{(i)}\left(x_{\mathrm{A}}-x_{\mathrm{B}}\right)^{i}+ \\
& \sum_{j=1}^{S} B_{\mathrm{AC}}^{(j)}\left(x_{\mathrm{A}}-x_{\mathrm{C}}\right)^{j}+ \\
& \sum_{k=1}^{t} B_{\mathrm{BC}}^{(k)}\left(x_{\mathrm{B}}-x_{\mathrm{C}}\right)^{k}
\end{aligned}
$$

though rarely are experimental data determined with sufficient precision to justify more than a few parameters.

Conceptually, these ideas can be extended to solute solubilities in binary solvent mixtures; however, there has
Table 2. Mathematical Representation of Anthracene

\begin{tabular}{|c|c|c|c|c|}
\hline \multirow[b]{2}{*}{ binary solvent system } & \multicolumn{2}{|c|}{ two-param eq 5} & \multicolumn{2}{|c|}{ eq 6} \\
\hline & $S_{i}^{a}$ & $\begin{array}{c}\% \\
\operatorname{dev}^{b}\end{array}$ & $\Lambda_{i j}^{\text {adj c }}$ & $\begin{array}{c}\% \\
\text { dev }\end{array}$ \\
\hline$n$-hexane +2 -butanol & $\begin{array}{r}1.165 \\
-0.081\end{array}$ & 0.3 & $\begin{array}{l}1.477 \\
1.481\end{array}$ & 0.5 \\
\hline n-heptane +2 -butanol & $\begin{array}{r}1.225 \\
-0.292\end{array}$ & 0.2 & $\begin{array}{l}1.109 \\
1.849\end{array}$ & 0.3 \\
\hline$n$-octane +2 -butanol & $\begin{array}{r}1.458 \\
-0.618\end{array}$ & 1.3 & $\begin{array}{l}0.949 \\
2.205\end{array}$ & 0.4 \\
\hline cyclohexane +2 -butanol & $\begin{array}{l}1.260 \\
0.206\end{array}$ & 0.6 & $\begin{array}{l}2.157 \\
1.345\end{array}$ & 0.5 \\
\hline methylcyclohexane + 2-butanol & $\begin{array}{r}1.447 \\
-0.009\end{array}$ & 1.2 & $\begin{array}{l}1.885 \\
1.593\end{array}$ & 0.6 \\
\hline 2,2,4-trimethylpentane +2 -butanol & $\begin{array}{r}1.070 \\
-0.213\end{array}$ & 0.8 & $\begin{array}{l}1.097 \\
1.633\end{array}$ & 0.4 \\
\hline
\end{tabular}
Solubilities in Several Binary Alkane (B) + 2-Butanol (C) Solvent Mixtures

a Combined NIBS/Redlich-Kister curve-fit parameters are ordered as $S_{0}$ and $S_{1}{ }^{b}$ Deviation $(\%)=(100 / N) \sum\left|\ln \left(x_{A}^{\text {calc }} / x_{A}^{\text {exp }}\right)\right| .{ }^{c}$ Adjustable parameters for the modified Wilson equation are ordered as $\Lambda_{\mathrm{BC}}^{\text {adj }}$ and $\Lambda_{\mathrm{CB}}^{\text {adj. }}$

never been up until recently a sufficiently large solid solute solubility data base to warrant computerized storage in equational form. With computerized data storage and retrieval becoming increasingly popular, it seems appropriate to discuss the various mathematical expressions that have been proposed in the chemical literature for describing the variation of solute solubility with binary solvent composition. Like the predictive expressions mentioned in the Introduction, mathematical representations provide a means to not only screen experimental data sets for possible outliers in need of redetermination but also facilitate interpolation at solvent compositions falling between measured data points.

Acree and co-workers $(19,20)$ suggested possible mathematical representations for isothermal solubility data based upon either a combined NIBS/Redlich-Kister model

$$
\begin{aligned}
& \ln x_{\mathrm{A}}^{\mathrm{sat}}=x_{\mathrm{B}}{ }^{\circ} \ln \left(x_{\mathrm{A}}^{\mathrm{sat}}\right)_{\mathrm{B}}+x_{\mathrm{C}}{ }^{\circ} \ln \left(x_{\mathrm{A}}^{\mathrm{sat}}\right)_{\mathrm{C}}+ \\
& x_{\mathrm{B}}{ }^{\circ} x_{\mathrm{C}}{ }^{\circ} \sum_{i=0}^{n} S_{i}\left(x_{\mathrm{B}}{ }^{\circ}-x_{\mathrm{C}}{ }^{\circ}\right)^{i}
\end{aligned}
$$

or modified Wilson equation (21)

$$
\begin{gathered}
\ln \left[a_{\mathrm{A}}(s) / x_{\mathrm{A}}^{\mathrm{sat}}\right]=1-x_{\mathrm{B}}{ }^{\circ}\left\{1-\ln \left[a_{\mathrm{A}}(s) /\left(x_{\mathrm{A}}^{\mathrm{sat}}\right)_{\mathrm{B}}\right]\right\} /\left(x_{\mathrm{B}}{ }^{\circ}+\right. \\
\left.x_{\mathrm{C}}{ }^{\circ} \Lambda_{\mathrm{BC}}^{\mathrm{adj}}\right)-x_{\mathrm{C}}{ }^{\circ}\left\{1-\ln \left[a_{\mathrm{A}}(s) /\left(x_{\mathrm{A}}^{\mathrm{sat}}\right)_{\mathrm{C}}\right]\right\} /\left(x_{\mathrm{B}}{ }^{\circ} \Lambda_{\mathrm{CB}}^{\mathrm{adj}}+x_{\mathrm{C}}{ }^{\circ}\right)
\end{gathered}
$$

where the various $S_{i}$ and $\Lambda_{i j}^{\text {adj }}$ "curve-fit" parameters can be evaluated via least-squares analysis. In eqs 5 and $6 x_{B}{ }^{\circ}$ and $x_{C}{ }^{\circ}$ refer to the initial mole fraction composition of the binary solvent calculated as if the solute were not present, $a_{\mathrm{A}}(s)$ is the activity of the solid solute, and $\left(X_{\mathrm{A}}^{\mathrm{sat}}\right)_{i}$ is the saturated mole fraction solubility of the solute in pure solvent $i$. The numerical value of $a_{\mathrm{A}}(s)=0.01049$ (1) used in the modified Wilson computations was calculated from

$$
\ln a_{\mathrm{A}}(s)=-\Delta_{\text {fus }} H_{\mathrm{A}}\left(T_{\mathrm{mp}}-T\right) /\left(R T T_{\text {mp }}\right)
$$

where $\Delta_{\text {fus }} H_{\mathrm{A}}$ is the molar enthalpy of fusion at the normal melting point temperature of the solute, $T_{\mathrm{mp}}$.

The ability of eqs 5 and 6 to mathematically represent the experimental solubility of anthracene in the six binary alkane +2 -butanol solvent systems is summarized in Table 2 in the form of curve-fit parameters and percent deviations in backcalculated solubilities for the two-parameter expressions. Careful examination of Table 2 reveals that both representations provide very reasonable mathematical descriptions for how the solubility of anthracene varies with solvent composition. For the most part, back-calculated and exper- 
imental values differ by less than $\pm 1.5 \%$, which is comparable to the experimental uncertainty. From a computational standpoint, eq 5 will likely be preferred because most research groups involved in reporting thermodynamic properties have computer programs for evaluating the Redlich-Kister coefficients. In the case of the two-parameter Redlich-Kister fit, the computations require only a simple linear least-squares analysis of

$$
\begin{array}{r}
{\left[\ln x_{\mathrm{A}}^{\mathrm{Bat}}-x_{\mathrm{B}}{ }^{0} \ln \left(x_{\mathrm{A}}^{\mathrm{sat}}\right)_{\mathrm{B}}-x_{\mathrm{C}}{ }^{0} \ln \left(x_{\mathrm{A}}^{\mathrm{sat}}\right)_{\mathrm{C}}\right] / x_{\mathrm{B}}{ }^{\circ} x_{\mathrm{C}}{ }^{0}} \\
\text { versus } x_{\mathrm{B}}{ }^{\circ}-x_{\mathrm{C}}{ }^{\circ}
\end{array}
$$

With this idea in mind, we recommend that not only the future presentation of experimental isothermal solubility data for slightly soluble solid solutes dissolved in binary solvent mixtures include a tabulation of the actual observed values but, if possible, that the solubility data be mathematically represented by eq 5 . Realizing that a single equation will not be applicable to all systems encountered, we further suggest eq 6 as an alternative mathematical representation for systems having extremely large solubility ranges and/or highly symmetrical $\ln x_{\mathrm{A}}^{\text {sat }}$ versus $x_{\mathrm{B}}{ }^{\circ}$ curves, such as the carbazole + alkane + tetrahydropyran systems reported previously (20).

\section{Literature Cited}

(1) Acree, W. E., Jr.; Rytting, J. H. J. Pharm. Sci. 1983, 72, 292.

(2) Judy, C. L.; Pontikos, N. M.; Acree, W. E., Jr. J. Chem. Eng. Data $1987,32,60$.
(3) Judy, C. L.; Pontikos, N. M.; Acree, W. E., Jr. Phys. Chem. Liq. $1987,16,179$.

(4) Choi, P. B.; Williams, C. P.; Buehring, K. G.; McLaughlin, E. J. Chem. Eng. Data 1985, 30, 403.

(5) Coon, J. E.; Troth, M.; McLaughlin, E. J. Chem. Eng. Data 1987, $32,233$.

(6) McCargar, J. W.; Acree, W. E., Jr. Phys. Chem. Liq. 1987, 17, 123.

(7) McCargar, J. W.; Acree, W. E., Jr. J. Pharm. Sci. 1987, 76, 572.

(8) Coon, J. E.; Sediawan, W. B.; Auwaerter, J. E.; McLaughlin, E. J. Solution Chem. 1988, 17, 519.

(9) Acree, W. E., Jr. Phys. Chem. Liq. 1990, 22, 157.

(10) Frodenslund, A.; Jones, R. L.; Rausnitz, J. M. AIChE J. 1975, 21, 1086.

(11) Bastos, J. C.; Soares, M. E.; Medina, A. G. Ind. Eng. Chem. Res. $1988,27,1269$.

(12) Burchfield, T. E.; Bertrand, G. L. J. Solution Chem. 1975, 4, 205.

(13) Acree, W. E., Jr.; Bertrend, G. L. J. Phys. Chem. 1977, 81, 1170.

(14) Acree, W. E., Jr. Thermodynamic Properties of Nonelectrolyte Solutions; Academic Press, Inc.: Orlando, FL, 1984.

(15) Acree, W. E., Jr. J. Chem. Eng. Data 1985, $30,70$.

(16) Judy, C. L.; Acree, W. E., Jr. Int. J. Pharm. 1985, 27, 39.

(17) Acree, W. E., Jr.; Pontikos, N. M.; Judy, C. L. Int. J. Pharm. 1986, $31,225$.

(18) Acree, W. E., Jr.; Tucker, S. A.; Zvaigzne, A. I. Phys. Chem. Liq. $1990,21,45$

(19) Acree, W. E., Jr.; Zvaigzne, A. I. Thermochim. Acta 1991, 178, 151.

(20) Acree, W. E., Jr.; McCargar, J. W.; Zvaigzne, A. I.; Teng, I.-L. Phys. Chem. Liq. 1991, 23, 27.

(21) Comer, J. F.; Kopecni, M. M. Anal. Chem. 1990, 62, 991.

Received for review April 16, 1993. Accepted September 27, 1993.• This research was supported in part by a grant from the National Science Foundation (Grant No. CTS-8922485).

- Abstract published in Advance ACS Abstracts, November 15, 1993. 